\title{
Chaetognath species-specific responses to climate regime shifts in the Tsushima Warm Current of the Japan Sea
}

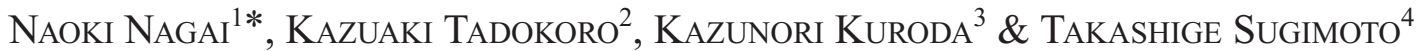 \\ ${ }^{1}$ Maizuru Marine Observatory, Maizuru-Shimofukui, Kyoto, 624-0946, Japan \\ ${ }^{2}$ Tohoku National Fisheries Research Institute, Shinhama-cho, Shiogama, Miyagi, 985-0001, Japan \\ 3 formerly Japan Sea National Fisheries Research Institute, Suido-cho, Niigata, 951-8121, Japan \\ ${ }^{4}$ Institute of Oceanic Research and Development, Tokai University, Orido, Shimizu-ku, Shizuoka, 424-8610, Japan
}

Received 26 September 2006; Accepted 16 January 2008

\begin{abstract}
Expanding the work in our previous paper (Nagai et al. 2006), which showed the close linkage of chaetognath species to changes in water temperature and reported their occurrence characteristics, chaetognath species-specific responses to climate forcing via water temperature fluctuations were ascertained by studying inter-annual linkages among climate-ocean-ecosystem elements. Using samples collected between 1972 and 2002 in the Japan Sea, an attempt was made to understand how the three dominant chaetognaths-Sagitta minima, S. nagae and S. enflata-respond to inter-annual variations of atmospheric signals and oceanic effects in the Tsushima Warm Current around climate regime shift years. Among ocean-atmosphere parameters, the winter monsoon was the most crucial for driving the ecosystem of the Japan Sea. No significant correlation with any of the other parameters was found with the southern oscillation index, but the winter monsoon index had a correlation with water temperature. The climate regime shift during 1976/77 occurred with anomalously cold water induced by a strong winter monsoon. The next climate regime shift $(1988 / 89)$ appeared with a warm water anomaly due to retention of warm water formed in winter by a weak winter monsoon and increased transport volume in the Tsushima Warm Current water. Chaetognath abundance and species numbers decreased during the colder regime and increased during the warmer regime. Responding to temperature in a species-specific manner, chaetognaths varied notably in abundance. Consequently, changes in species numbers and switching of dominant species occurred. Thus, chaetognath species could be a significant indicator of climate events that influence the ecosystem in the Japan Sea.
\end{abstract}

Key words: chaetognath species-specific response, climate regime shift, inter-annual variations, Japan Sea, water temperature

\section{Introduction}

The Chaetognatha, a phylum of invertebrates, comprises about 115 species that inhabit the world's oceans (Bieri 1991). They are well known as useful indicators of specific water masses and are important carnivores of secondary producers in the ecosystem (Bieri 1959, Alvariño 1965, Terazaki 2001).

The Japan Sea is known as a semi-enclosed deep marginal sea containing a homogeneous water mass called the "Japan Sea Proper Water" (Uda 1934) and peculiar hydrographical characteristics with intrusion of the Tsushima Warm Current (TWC) water and subarctic water masses (Shuto 1982, Kim et al. 2002). The Sea has recently been investigated with respect to the ocean-atmosphere interac-

\footnotetext{
*Corresponding author: Naoki Nagai; E-mail: n-nagai@mt.kishou.go.jp
}

tion induced by climate changes. The Japan Sea is regarded as a suitable experimental site for "a world ocean in miniature" (Ichiye 1984) to verify ecosystem responses to global warming, because the semi-enclosed deep Japan Sea has a richness of ecosystems caused by the inflow of the subtropical TWC, to the subarctic circulation, and has the formation of sea ice in winter. In recent years, international cooperative research projects, such as CREAMS (Circulation Research of East Asian Marginal Seas) and NEAR-GOOS (North East Asian Regional Global Ocean Observing System), have been conducted there and substantial scientific contributions have been made.

Since 1972, the Maizuru Marine Observatory (MMO) of the Japan Meteorological Agency (JMA) has carried out routine oceanographic and plankton observations in the Japan Sea to assess the state of marine pollution. A few studies related to long-term climate fluctuations using the 
data obtained from these observations along the PM transect (pollution line in the Japan Sea by MMO, Fig. 1) have been published (physical: Isoda \& Korematsu 1995, Senjyu \& Sudo 1996, Kim \& Isoda 1998, Minami et al. 1999a, b; plankton: Imai \& Ebara 1989, Kubo \& Ebara 1992, Chiba \& Saino 2002, 2003, Nagai et al. 2006).

After the concept of climate regime shift was recognized by Kawasaki (1983) and expressed as a regime problem by Lluch-Belda et al. (1989), strong attention has been paid to climatic impacts on ecosystems. Kawasaki (2003) explained that the regime in the ecosystem shifts every few decades due to interaction by ocean-atmosphere forcing events. Likewise, Hanawa \& Yasunaka (2003) determined climate regime shift years in the 1900s and pointed out that a climate regime shift is synonymous with a "climatic jump" in meteorology - defined as abrupt changes in surface water temperature in the north Pacific Ocean relating to atmospheric circulation on a global-scale.

Nagai et al. (2006) reported the close linkage of chaetognath species to water mass properties (especially temperature) and the characteristics of their occurrence. Elaborating on this previous research, the present paper describes how the three dominant chaetognath species in the Japan Sea (Nagai et al. 2006) respond to climate forcing events via water temperature changes and how they can be used as indicators of the state of the Japan Sea ecosystem. To accomplish this, long-term inter-annual data sets of the dominant chaetognath species as well as physical parameters collected by the R/V Seifu Maru of MMO during 1972 to 2002 were analyzed in relation to the climate indices of Air Temperature (AT), Asian winter Monsoon Index (MOI) and Southern Oscillation Index (SOI).

\section{Materials and Methods}

\section{Hydrographic conditions}

Water samples were collected at multiple depths using Nansen bottles from 1972 to 1987, and by Niskin bottles in combination with CTD casts from 1988 to 2002. Water temperature (WT) and salinity (SAL) data represent the integrated-average values of the $0-100 \mathrm{~m}$ layer, as warmwater and mixed-water species of chaetognaths are mostly distributed in the upper $100 \mathrm{~m}$ of the TWC water (Terazaki 1993, Nishihama \& Hirakawa 1998). The eastward (positive) volume transport (VT) of TWC water was calculated from the geostrophic current assuming $500 \mathrm{dbar}\left(10^{4} \mathrm{~Pa}\right)$ as an indicative level of no motion along the PM transect (from Station PM 1 to 10, Fig. 1). This assumption was based on Minami et al. (1987) who considered that $500 \mathrm{dbar}\left(10^{4} \mathrm{~Pa}\right)$ is a more appropriate and better approximation of no motion when discussing VT calculations in terms of the PM transect.

\section{Climate indices}

SOI is an index of the strength of the trade winds, and

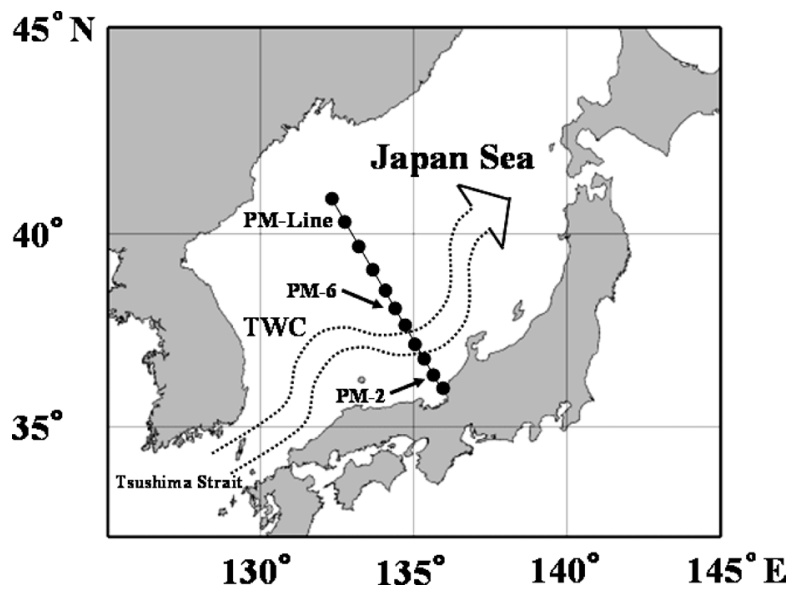

Fig. 1. Map of the Japan Sea and the PM sampling transect line of the Maizuru Marine Observatory. TWC represents the Tsushima Warm Current.

positive (negative) values indicate a strong (weak) phase. It is calculated according to differences in air pressure between Darwin and Tahiti. MOI represents the difference in air pressure between Irkutsk in Russia and Nemuro in Japan. Both SOI and MOI data obtained from the home page of the JMA were used (monthly mean values from December to February during 1972 to 2002). AT was recorded at Saigo weather station, Okinosima Island, near the PM transect located in the southwestern part of the Japan Sea. The climatic regime shift years in the present study were examined for both 1976/77 and 1988/89 with regard to Yasunaka \& Hanawa (2002), and a possible regime shift year in 1998/99 with regard to Minobe (2000).

Framing of yearly anomaly time-series: Year-to-year anomaly time-series were made by averaging the annual and seasonal data to compare significant tendancies above average (positive phase) and below average (negative phase) for each parameter.

AT, WT, SAL, VT, chaetognath abundance [Ch(A)], and species numbers $[\mathrm{Ch}(\mathrm{N})]$ were averaged seasonally for each year. Annual data of significant WT, SAL, VT, and Ch(A) were used to create yearly averages. Monthly mean values from December to February of the climate indices MOI and SOI were also averaged for each year during the entire study period (1972-2002). Positive phases and negative phases of SOI represented La Niña and El Niño events, respectively.

\section{Zooplankton sampling}

Observations were made during each of the four seasons during 1972 to 2002 along the PM transect of JMA: winter (late-January to early-March except 1972), spring (lateApril to late-May), summer (early-July to early August), and autumn (late-September to late-October). The five stations extending from PM $2\left(36^{\circ} 25^{\prime} \mathrm{N}, 135^{\circ} 39^{\prime} \mathrm{E}\right)$ to PM 6 $\left(38^{\circ} 09^{\prime} \mathrm{N}, 134^{\circ} 24^{\prime} \mathrm{E}\right)$ usually fall in the TWC region (Mi- 


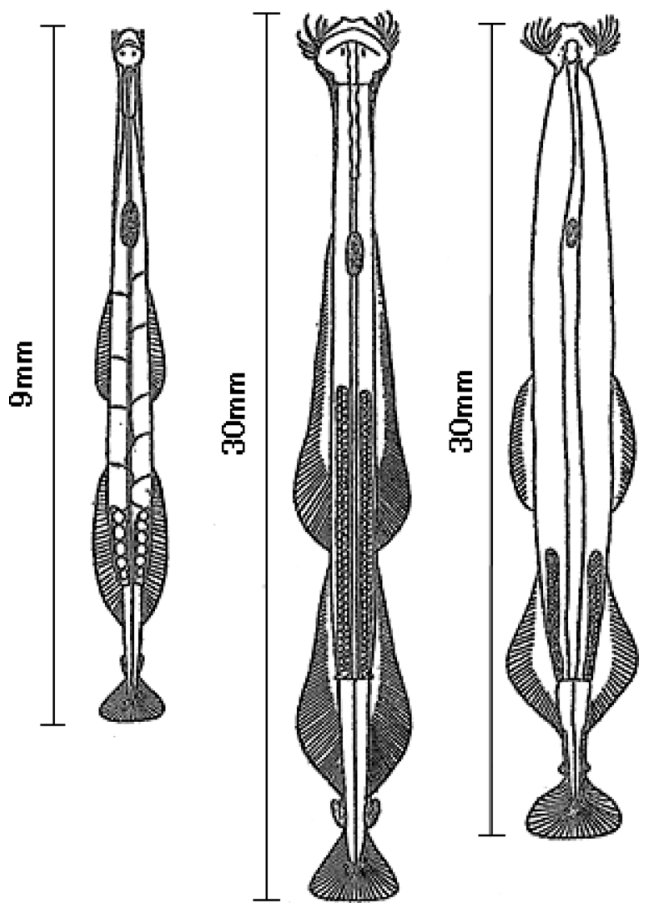

Fig. 2. Matured individuals of the three dominant species of chaetognaths; Sagitta minima (left, maximum body length: $9 \mathrm{~mm}$ ), S. nagae (middle, max. body length: $30 \mathrm{~mm}$ ), S. enflata (right, max. body length: $30 \mathrm{~mm}$ ) after Kitou (1967).

nami et al. 1987). The zooplankton samples were collected by vertical hauls using a NORPAC net (mouth diameter $45 \mathrm{~cm}$, mesh size $0.33 \mathrm{~mm}$ : Motoda 1957) with a flowmeter from $150 \mathrm{~m}$ depth to the surface and were preserved in 5\% formalin sea water. Chaetognath species were identified to species level and enumerated by microscopic analysis. Four dominant species were observed in abundance: Sagitta elegans Verrill (cold-water sp.), S. enflata Grassi (warm-water sp.), S. minima Grassi (mixed-water sp.), and S. nagae Alvariño (mixed-water sp., Nagai et al. 2006). The latter three dominant species in TWC water were selected for further analysis in the present study, while $S$. elegans, a cold-water species, is distributed in the water column containing the cold Proper Water according to Terazaki (1993, Fig. 2).

\section{Statistical methods}

We used regression analysis to estimate the relationship among time series. Autocorrelation in time series can complicate statistical inference in correlation analyses (Pyper \& Peterman 1998). To address this problem, we applied the following formula (Pyper \& Peterman 1998, Mackas et al. 2001) for the effective degrees of freedom, $N^{*}$, of the correlation between two time series, $\mathrm{X}$ and $\mathrm{Y}$ :

$$
\frac{1}{N^{*}}=\frac{1}{N}+\frac{2}{N} \sum_{j=1}^{N / 2} \frac{(N-j)}{N} \operatorname{rxx}(j) r y y(j)
$$

where $N$ is the number of annual data points in each time series, and $r x x(j)$ and $r y y(j)$ are the sample autocorrelations of $\mathrm{X}$ and $\mathrm{Y}$ at time lag $j$ (yearly increments).

\section{Results}

\section{Inter-annual variations of ocean-atmosphere factors}

Time-series data of the WT yearly average revealed that after a warm phase from 1972 to 1975, the WT was hovering near the average until 1980, and then passed through a remarkably cold phase from 1981 to 1986 with the lowest value in 1984. Since 1990, a warm phase has generally remained except for a small cold phase from 1993 until 1996. On the other hand, the SAL yearly average fluctuated with a periodicity of 6 to 8 years. Between 1988 and 1990, WT and SAL time-series switched from a pattern of parallel phase to opposite phase (Fig. 3c, d).

On the basis of yearly average values, VT had positive phases during 1972 to 1975 and 1990 to 2002 with the highest in 1974 and 2002 respectively, and negative phases during 1978 to 1988 with the lowest in 1985 (Fig. 3e). In general, VT signals seemed in agreement with the WT trends in both the 1976/77 and the 1988/99 climate regime shifts. It was found that WT correlates positively to VT, being significant $r=+0.49(p=0.05)$ for winter (Table 1). According to Nakadate et al. (2003), a significant negative correlation exists between VT and MOI during all four seasons using three year's running mean values, though no significant correlation was found in the present study. Importantly, SAL only had significant negative correlations with VT $(r=-0.48, p=0.01 ; \mathrm{r}=-0.42, \mathrm{p}=0.05)$ in winter and autumn, respectively (Table 1 ).

Somewhat similar fluctuation patterns of positive or negative correlations were found by year between SOI and MOI, except around the climate regime shift years 1976/77 and 1988/99 where they were in opposite phase (Fig. 3a, b). However, there was no significant correlation $(\mathrm{r}=+0.23)$ between SOI and MOI in winter.

\section{Correlations among controlling factors in ocean-atmos- phere process}

The correlation coefficients between WT and SAL were significantly positive $(r=+0.42, p=0.05)$ in autumn and slightly negative in winter (Table 1a-d). As for correlation coefficients between the seasons for both WT and SAL, WT had more significant correlation coefficients than SAL except from autumn to winter. SAL had significant confidence values between seasons except from spring to summer (Table 1e). These results indicate that WT of a newly mixed water mass in winter remained in the warm phase until autumn, whereas, SAL continued to be unchanged for the whole year. Considering the relation to atmospheric factors, WT was significantly related to MOI $(\mathrm{r}=-0.38--0.61, \mathrm{p}=0.01-0.05)$ in winter, spring and summer and also to AT $(r=+0.35-+0.63, p=0.01-0.05)$ 
Table 1. The correlation coefficient among SOI (southern oscillation index), MOI (winter monsoon index), AT (air temperature), WT (water temperature), SAL (salinity), and VT (volume transport) in winter (a), spring (b), summer (c) and autumn (d). The lowest panel (e) shows correlation coefficients of both water temperature and salinity between each season. The asterisks represent significance at the $95 \%$ level $*$ and $99 \%$ level $* *$. NS signifies the correlation coefficients were less than $\mathrm{r}= \pm 0.10$, near zero. $\mathrm{N}$ is represented in round brackets next to the correlation coefficient.

(a)

\begin{tabular}{llllll}
\hline Winter & \multicolumn{2}{c}{ AT } & WT & SAL & VT \\
\hline SOI & -0.123 & $(23)$ & NS & NS & $0.281 \quad(28)$ \\
MOI & $-0.826^{* *}(21)$ & $-0.548^{* *}(25)$ & NS & NS \\
AT & & & $0.632^{* *}(25)$ & NS & $-0.185 \quad(30)$ \\
WT & & & -0.298 & $(30)$ & $0.491^{*}(20)$ \\
SAL & & & & $-0.484^{* *}(30)$ \\
\hline
\end{tabular}

(b)

\begin{tabular}{|c|c|c|c|c|c|c|c|c|}
\hline \multirow{2}{*}{$\begin{array}{l}\text { Spring } \\
\text { SOI }\end{array}$} & \multicolumn{2}{|c|}{$\mathrm{AT}$} & \multicolumn{2}{|l|}{ WT } & \multicolumn{2}{|c|}{ SAL } & \multicolumn{2}{|c|}{ VT } \\
\hline & -0.123 & (31) & & NS & & NS & & NS \\
\hline MOI & $-0.494^{*}$ & (25) & $-0.605^{* *}$ & (24) & & NS & & NS \\
\hline AT & & & $0.374 *$ & (31) & -0.215 & (31) & 0.270 & (20) \\
\hline WT & & & & & 0.127 & (20) & 0.274 & (24) \\
\hline SAL & & & & & & & -0.155 & (22) \\
\hline
\end{tabular}

(c)

\begin{tabular}{|c|c|c|c|c|c|c|c|c|}
\hline \multirow{2}{*}{$\begin{array}{l}\text { Summer } \\
\text { SOI }\end{array}$} & \multicolumn{2}{|c|}{ AT } & \multicolumn{2}{|c|}{ WT } & \multicolumn{2}{|c|}{ SAL } & \multicolumn{2}{|c|}{ VT } \\
\hline & & NS & & NS & 0.100 & (31) & 0.144 & (31) \\
\hline MOI & -0.224 & (31) & $-0.380 *$ & (29) & & $\mathrm{NS}$ & & NS \\
\hline AT & & & 0.351 & (30) & -0.235 & (26) & & NS \\
\hline WT & & & & & 0.134 & (25) & 0.453 & (12) \\
\hline SAL & & & & & & & -0.235 & (31) \\
\hline
\end{tabular}

(d)

\begin{tabular}{|c|c|c|c|c|c|c|c|c|}
\hline \multirow{2}{*}{$\begin{array}{l}\text { Autumn } \\
\text { SOI }\end{array}$} & \multicolumn{2}{|c|}{ AT } & \multicolumn{2}{|c|}{ WT } & \multicolumn{2}{|c|}{ SAL } & \multicolumn{2}{|c|}{ VT } \\
\hline & 0.111 & (28) & 0.169 & (23) & & NS & & NS \\
\hline MOI & -0.335 & (30) & -0.261 & (31) & 0.282 & (25) & & NS \\
\hline AT & & & 0.278 & (27) & -0.333 & (23) & & NS \\
\hline WT & & & & & $0.424^{*}$ & (30) & 0.119 & (31) \\
\hline SAL & & & & & & & $-0.415^{*}$ & (31) \\
\hline
\end{tabular}

(e)

\begin{tabular}{cllllll}
\hline Season & $\mathrm{WI} \rightarrow \mathrm{SP}$ & \multicolumn{2}{c}{$\mathrm{SP} \rightarrow \mathrm{SU}$} & $\mathrm{SU} \rightarrow \mathrm{AU}$ & $\mathrm{AU} \rightarrow \mathrm{WI}$ \\
\hline $\mathrm{WT}$ & $0.620^{* *}(30)$ & $0.483^{*}$ & $(21)$ & $0.642^{* *}(28)$ & $\mathrm{NS}$ \\
$\mathrm{SAL}$ & $0.608^{*}(14)$ & 0.359 & $(21)$ & $0.577^{* *}(29)$ & $0.460 *(23)$ \\
\hline
\end{tabular}

in the same seasons (Table $1 \mathrm{a}-\mathrm{c}$ ). The significant correlations between MOI and AT were $r=-0.83(p=0.01)$ in winter and $r=-0.49(p=0.01)$ in spring (Table 1a, b).

Thus, the apparent factors affecting WT in the ocean-atmosphere process are MOI (winter, spring, and summer: negative), AT (winter, spring, and summer: positive) and
VT (winter and summer: positive). These results show that positive MOI may induce low WT and AT at the same phase, and high VT may drive warm WT for each season. 

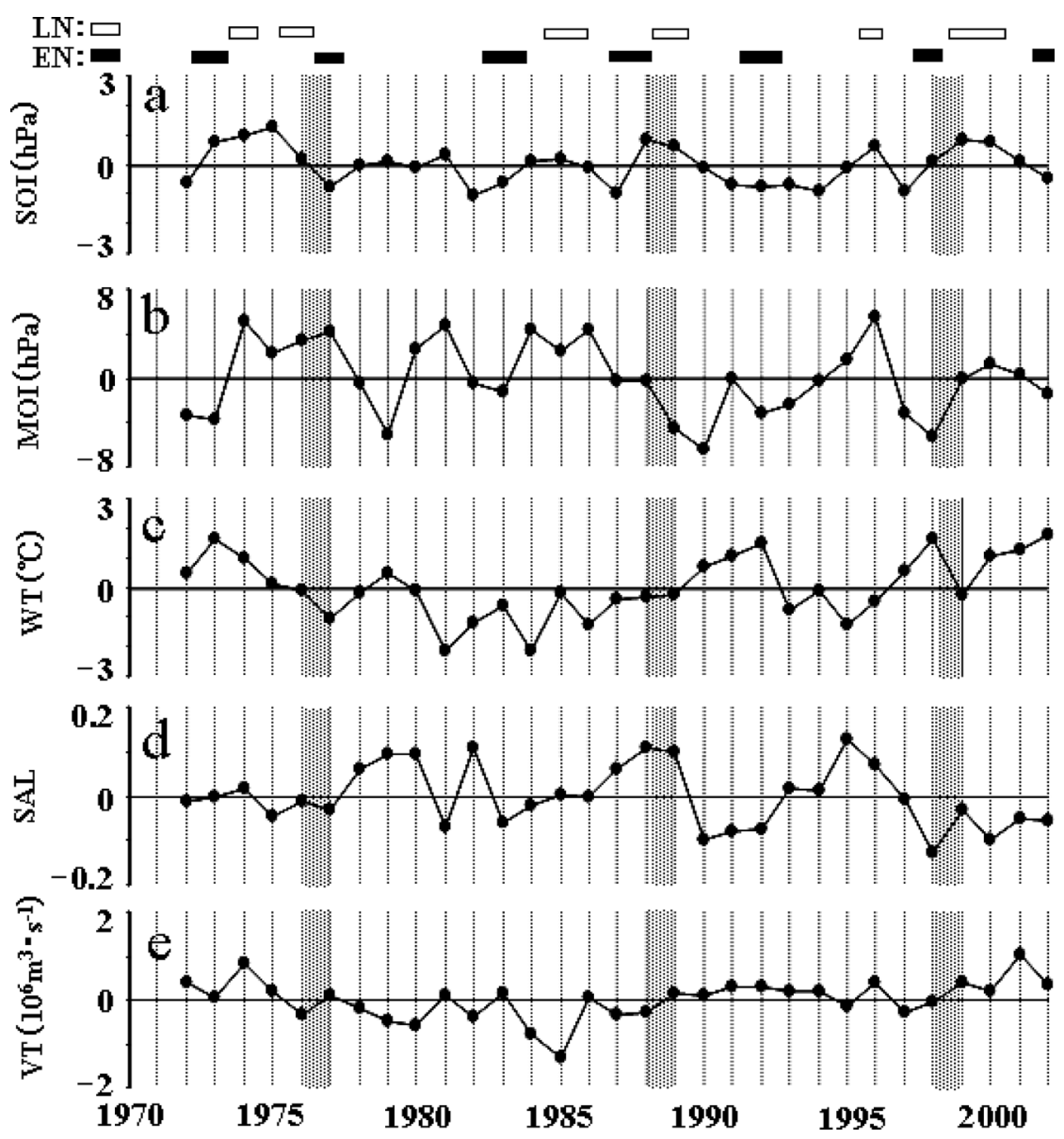

Fig. 3. Inter-annual variations of SOI (a, southern oscillation index), MOI (b, winter monsoon index), WT (c, water temperature), SAL (d, salinity), and VT (e, volume transport), represented by anomalies normalized from the averages during 1972 to 2002. The former two indices show monthly average values during December to February and the latter three elements indicate yearly average values. Shaded year bars show climate regime shift years. EN (El Niño periods) and LN (La Niña periods) are shown by lateral bars at the top.

\section{Chaetognath species-specific responses to ocean-atmos- phere factors around climate regime shifts}

On the basis of the above observations and our previous analysis (Nagai et al. 2006), a series of close linkages among different inter-annual parameters in ocean-atmosphere ecosystems could be found by focusing on climate regime shift years (Fig. 4).

(1) The case of the 1976/77 climate regime shift. The positive MOI during 1974 to 1977 decreased AT in winter and spring directly. These cold winter events seemed to have a tele-connection with the La Niña period of 1973 to 1975. Annual VT tended to decrease from 1976 to 1980, but a below average VT phase had already begun from spring 1975. In response to the positive MOI, WT started dropping from winter 1975, followed by cold phases in both spring and summer from 1975 to 1981. In consequence, annual WT remained in a long cold phase from 1976 onwards, while annual SAL shifted to a positive phase during winter to spring in 1978 under the influence of nega- tive MOI during 1978 to 1979 , resulting in increased vertical mixing of the water mass (Fig. 4).

For one decade beginning from 1978, one year later than the regime shift year, the annual chaetognath abundance $\mathrm{Ch}(\mathrm{A})$ was less than the average of the entire study period (1972-2002). However, the low abundance in $\mathrm{Ch}(\mathrm{A})$ was first noticeable due to a lowering of WT from winter and spring 1976, and continued until almost 1991 (Fig. 4). No clear change in species numbers was noticed except during springtime in response to WT around the regime shift year (Nagai et al. 2006) (Fig. 4). During the low abundance from 1976, Sagitta minima surpassed $S$. nagae as the dominant species in winter, but in spring and summer, $S$. nagae tended to outnumber $S$. minima during the colder and highly saline years from 1977 to 1990 . The shift in dominance from S. minima to S. nagae in spring 1977 and summer 1978 might have been caused by the colder WT anomaly in winter 1975 . However, in autumn, S. minima maintained dominance until about 1982, because the WT was around the average till 1982 (Fig. 4). 
(2) The case of the 1988/89 climate regime shift. Because MOI became negative from 1987 accompanied with rising AT, warm winters lasted until 1993. This phenomenon seemed to be driven partly by the El Niño event from autumn 1986 to winter 1988. Annual VT increased from the lowest value in 1985 and shifted to a positive phase in 1989, beginning from winter 1988. Also, annual WT began to rise in 1989 , derived from winter and spring 1988, and consequently, cold water was replaced by warm water in all four seasons of 1990. On the other hand, annual SAL from 1987 to 1989 appeared higher than the average in spring, summer, and autumn, but changed to lower than the average from 1990 to 1992, mainly in autumn (Fig. 4).

$\mathrm{Ch}$ (A) began to increase in response to the warm, low salinity phase from winter 1988 and autumn 1990, and stayed above average from 1991 to 2000. At the same time, $\mathrm{Ch}(\mathrm{N})$ increased in accordance with the abundance during spring to autumn from 1990, because of the appearance of warm water species of subtropical origin (Nagai et al. 2006). These changes were triggered by the occurrence of warm WT anomalies in autumn 1987, and winter and spring 1988. Around the regime shift year S. minima re-

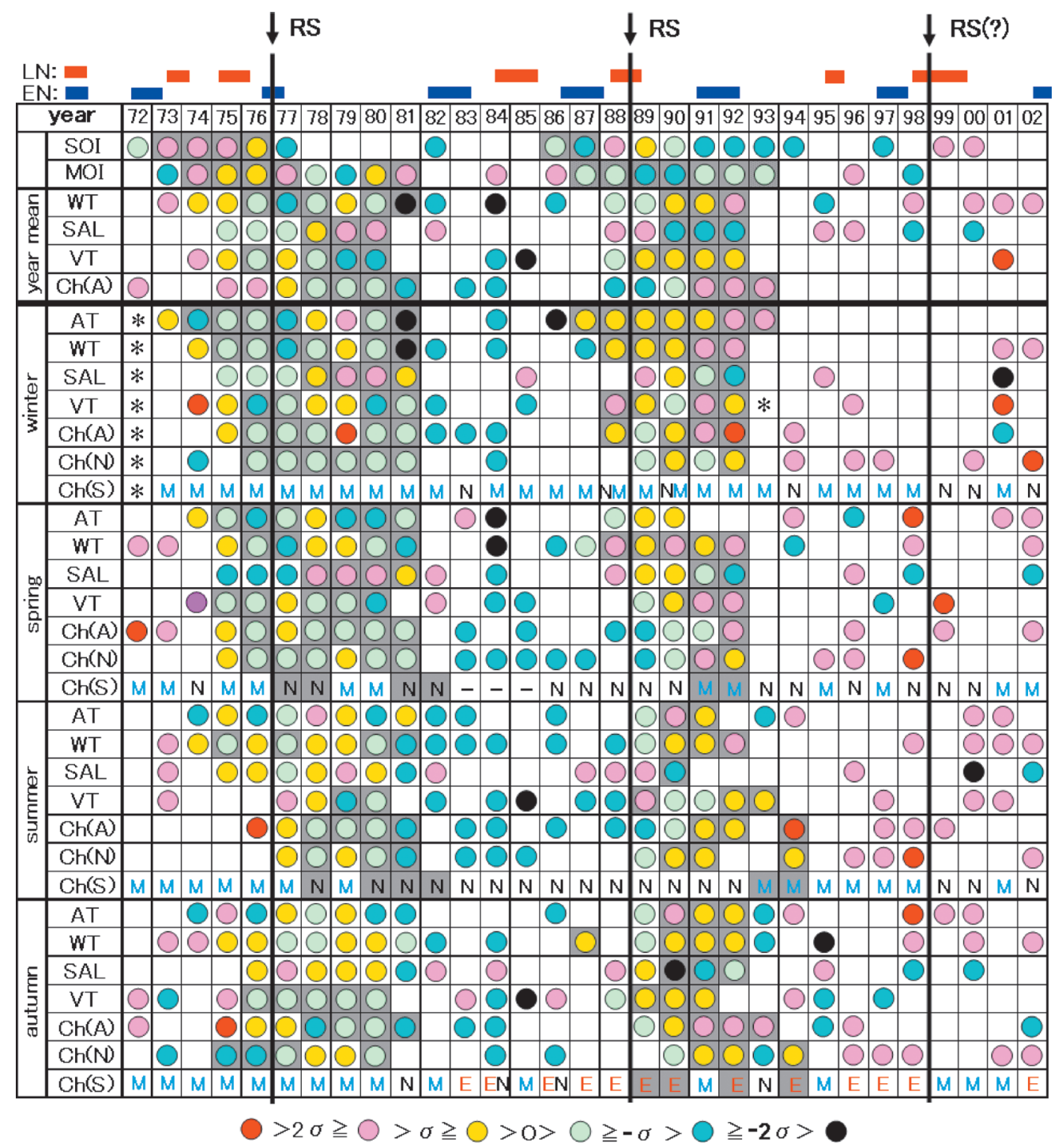

Fig. 4. Inter-annual variations of SOI (southern oscillation index), MOI (winter monsoon index), AT (air temperature), WT (water temperature), SAL (salinity), VT (volume transport), $\mathrm{Ch}(\mathrm{A})$ (chaetognath abundance), and $\mathrm{Ch}(\mathrm{N})$ (species numbers) are represented by the six classes of standard deviations above $\pm \sigma$ from the averages during 1972 to 2002. Blank years show standard deviations less than $\pm \sigma$, near the averages, except for close linkage years around regime shifts. MOI and SOI represent monthly averages for three months during December to February. $\mathrm{Ch}(\mathrm{S})$ in each season shows the dominant species of each year. Alphabetic M, N and E signify Sagitta minima, S. nagae and S. enflata, respectively. The sign (-) in spring during 1983 to 1985 shows no occurrence of dominant species. RS at the top with small arrows shows the climate regime shift years. EN (El Niño periods) and LN (La Niña periods) are also shown at the top. Shaded parts show a series of close linkage years among each parameter around the climate regime shifts (judged subjectively). The sign (*) in winter signifies no data. 
mained dominant in winter, while $S$. nagae remained dominant in spring. Sagitta nagae was also dominant during summer from 1980 to 1992 , but was replaced by S. minima from 1993 to 1998. In autumn, both S. enflata and S. minima tended to increase in 1985, and the more adaptable $S$. enflata was dominant from 1986 until 1998 in response to low salinity values (Fig. 4).

(3) The case of a possible 1998/99 climate regime shift. From 1997 to 1999, warm winters prevailed in response to negative MOI. Annual VT shifted from a negative to a positive phase in 1999, showing an increasing signal there after. Annual WT was warm for nearly all years between 1997 and 2002, accompanied by a lower phase than the average for annual SAL. At the same time, WT and SAL during summer in particular revealed a concurrent signal with opposite phases. Also, $\mathrm{Ch}(\mathrm{A})$ showed no clear change, but $\mathrm{Ch}(\mathrm{N})$ conspicuously increased in the 1990s (Nagai et al. 2006). Subsequently, the dominant species seemed to switch from $S$. minima to $S$. nagae in winter and summer 1999, and from S. enflata to S. minima in autumn 1999 (Fig. 4).

\section{Discussion}

\section{Two physical-biological coupling processes in the Japan Sea ecosystem}

The present analysis indicates that we can schematically explain two physical-biological processes using the three dominant chaetognath species in relation to WT and TWC water from the winter monsoon forcing the Japan Sea ecosystem (Fig. 5). This conclusion, being in accordance with the opinion of Sekine (1992), means that switching of the two different processes might be regulated by the strength of the winter monsoon.

One case is a cold winter regime in which WT values during winter and spring remain anomalously colder than average due to cooling induced by a strong monsoon in winter. This cold WT anomaly persists through summer and autumn, because VT of TWC water is small from winter to summer and doesn't increase WT. Subsequently, the WT values from winter to spring become considerably colder than the specific optimum WT ranges of chaetognath species, which decreases their abundance and species numbers through mortality (Nagai et al. 2006). Lower than average WT in summer and autumn causes a decrease in chaetognath abundance and species numbers due to poor conditions for their growth and spawning. However, Sagitta nagae, being more adaptive to lower WT than $S$. minima, is dominant from spring to summer for their spawning season. In other words, this cold winter regime is a process that results in chaetognath species-specific responses to a colder winter, occurring mainly during winter to spring and continuing until summer and autumn (Fig. 5).

The other case is opposite, a warm winter regime that occurs because of a warm anomaly created by the persistence of warmer water formed in winter and the increase in VT of TWC water during weak winter monsoon years. That is, lateral advection of TWC water induces a rise in WT and an increase in abundance and numbers of chaetognath species. As a result, the dominant species changes from $S$. nagae to $S$. minima in summer and from $S$. minima to $S$. enflata in

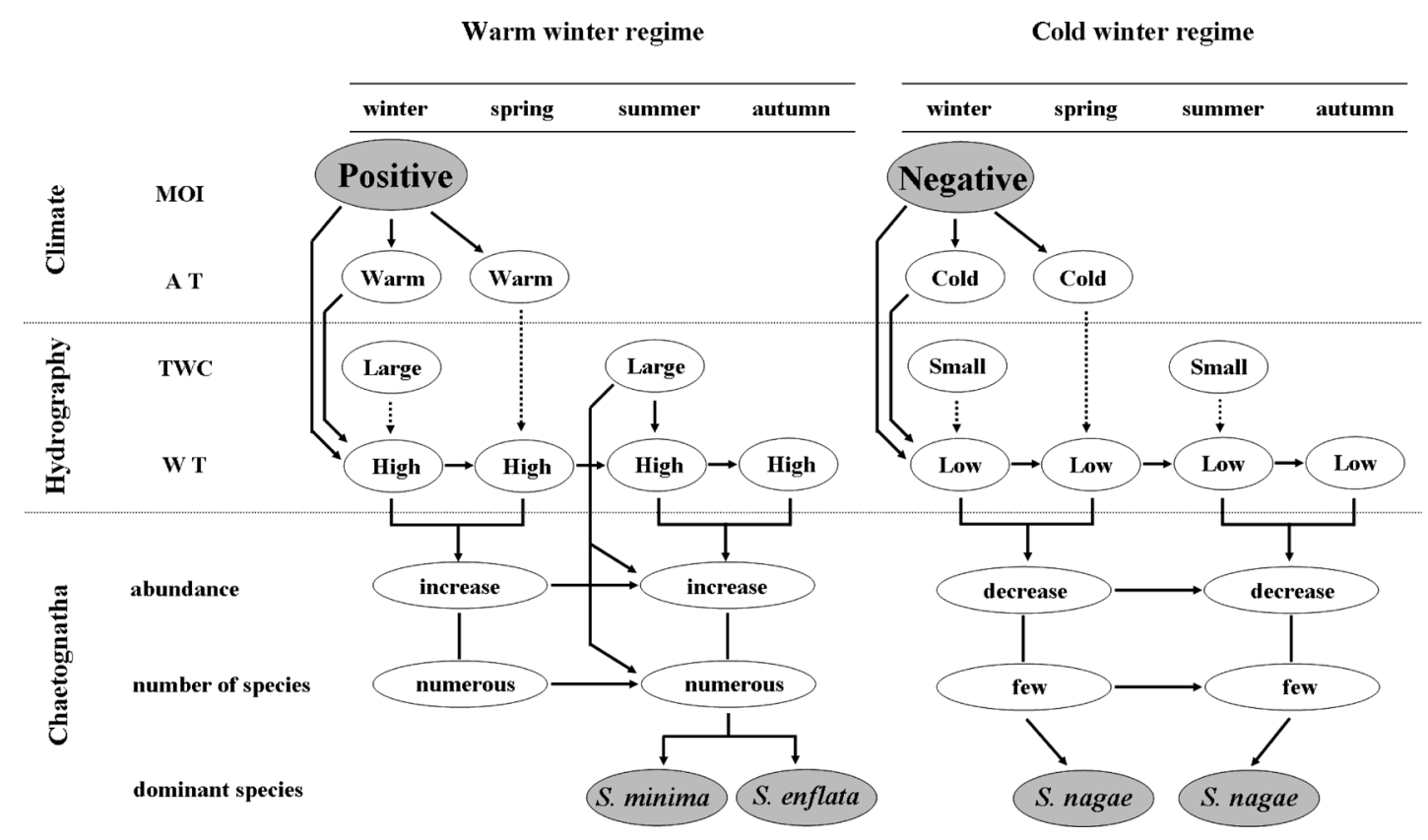

Fig. 5. Schematic physical-biological coupling processes during the two different winter regimes from the climate signals to chaetognath species occurrence in the Japan Sea, with the starting points initiated by the winter monsoon. Solid lines show major factors affecting energy flow and dotted ones minor. 
autumn, because their adaptative ability to warmer WT is as follows: S. enflata $>S$. minima $>S$. nagae (Nagai et al. 2006). This warm winter regime is a process under the influence of TWC water that induces chaetognath speciesspecific responses mainly during summer to autumn (Fig. 5).

\section{Leading effects of a winter monsoon in the Japan Sea}

The leading and cooling effects on WT by a winter monsoon have already been pointed out in the Japan Sea and also in the western North Pacific. For example, these include relations to the weather and climate in Japan as introduced by Matsumura \& Xie (1998), WT along the Japanese coast by Watanabe et al. (1986), the oceanic circulation in the Japan Sea by Sekine (1992), climate regime shifts by Yasuda \& Hanawa (1999) and the leading effects on WT off Sanin in the southern Japan Sea by Senjyu (2003). Thus, the winter monsoon is considered to be a leading factor that drives the circulation pattern like a small-scale conveyorbelt in the Japan Sea (Gamo \& Horibe 1983, Tsunogai et al. 1993, Kim \& Kim 1996).

We should point out from Fig. 4 that it requires more than two continuous years for annual WT to shift phase from the average in response to MOI. In particular, the shift to a colder than average WT phase may mainly depend upon the cooling effect of the winter monsoon, which affects the inter-annual extension of not only the surface mixed layer (warm TWC water), but also the subsurface layer (cold mid-water) which is closely correlated with the mixed layer depth (Kim \& Isoda 1998). Thus, the change of winter monsoon from weak to strong during the 1976/77 climate regime shift and the cold phase in WT after the regime shift might have resulted in a decrease in chaetognath abundance and species numbers. The reverse trend during the 1988/89 climate regime shift and the warm phase with low SAL might have caused them to increase.

Since the next climate regime shift was predicted to move towards a cold WT phase, the changes noted in 1998/99 (intensified warm WT and low SAL, increased VT) might not be classifiable as a climate regime shift.

\section{El Niño-Southern Oscillation (ENSO) cycle impacts on the Japan Sea ecosystem and ecosystem responses}

Figure 4 also indicates that the climate-ocean-ecosystem in the Japan Sea may be affected through tele-connection by SOI preceding MOI. This has also been suggested by other researchers. For example, Watanabe et al. (1986) indicated that the rise in WT from summer to autumn may mainly depend on subtropical warm water relating to SOI that flows into the Japan Sea. Yasunaka \& Hanawa (2003) pointed out that the climate regime shift years are generally coupled with SOI cycles (El Niño and La Niña). Furthermore, Chiba \& Saino (2003) explained that ENSO cycles influence lower trophic levels in the Japan Sea ecosystem. Sugimoto et al. (2001) showed that cool summers and warm winters in the East Asian Marginal Seas may occur during El Niño events. Finally, Park \& Oh (2000) have also reported that the East Asian Marginal Seas are related by tele-conection to the El Niño area with a cyclic period of six years for surface WT.

There are few papers on the response of the Japan Sea ecosystem to climate forcing. This may be due to the absence of long-term biological data-sets needed to analyze them. In general, ecosystem changes are represented by species-specific responses, so animal taxa must be identified to the species level. In the case of the Maizuru Marine Observatory zooplankton samples, species level identification has been completed only with chaetognaths. Accordingly, in this study we are unable to discuss biological factors that affect chaetognath abundance and the influences chaetognaths have on lower trophic levels.

Because WT directly affects chaetognath abundances and species numbers (Nagai et al. 2006), each species responds specifically to WT in the Japan Sea ecosystem. This study found that the dominant chaetognath species may respond to WT in a species-specific way under the influence of climate forcing events. Thus, the ecosystem may change as a result of coupled species-specific responses and inter-specific relations.

Chaetognath species-specific responses seem to begin almost simultaneously with abrupt and persistent changes in WT from certain seasons prior to the climate regime shift year. However, the replacement of dominant species, as a result of inter-specific responses, appears after a time lag. Other studies report similar phenomena synchronized with climate regime shifts occurring among some commercial pelagic fishes, such as the Japanese sardine (Klyashtorin \& Smirnov 1995, Zhang et el. 2000), the Pacific herring (Nagasawa 2001), and the common squid (Sakurai et al. 2000). However, large time lags tend to occur in higher trophic level animals, such as demersal fishes, mammals and so on, because they have an older maturity age, and higher trophic level animals require more time to respond to WT directly through recruitment and complex food chains.

\section{Acknowledgements}

We are grateful to Dr. Pravakar Mishra of the Integrated Coastal Marine Area Management, Project Directorate, Department of Ocean Development, at Chennai in India and Dr. Travis Johnson of the Ocean Research Institute of Tokyo University for critical reading and commenting on the English manuscript. We would also like to thank the research scientists and crew of R/V Seifu Maru.

\section{References}

Alvariño A (1965) Chaetognaths. Oceanogr Mar Biol Ann Rev 3: 115-194.

Bieri R (1959) The distribution of the planktonic Chaetognatha in the Pacific and their relationship to the water masses. Limnol 
Oceanogr 4: 1-28.

Bieri R (1991) Systematics of Chaetognatha. In: Biology of chaetognaths (eds Bone Q, Kapp H, Pierrot-Bults AC). Oxford Univ Press, Oxford, pp. 122-136.

Chiba S, Saino T (2002) Interdecadal change in the upper water column environment and spring diatom community structure in the Japan Sea: an early summer hypothesis. Mar Biol Prog Ser 231: 23-35.

Chiba S, Saino T (2003) Variation in mesozooplankton community structure in the Japan/East Sea (1991-1999) with possible influence of the ENSO scale climatic variability. Prog Oceanogr 57: 317-339.

Gamo T, Horibe Y (1983) Abyssal circulation in the Japan Sea. J Oceanogr Soc Jpn 39: 220-230.

Hanawa K, Yasunaka S (2003) Regime shifts occurred on the sea surface field of northern Hemisphere in the past 100 years. Kaiyo Monthly 35(2): 80-85. (in Japanese)

Ichiye T (1984) Some problems of circulation and hydrography of the Japan Sea and the Tsushima Current. In: Ocean Hydrodynamics of the Japan and East China Seas (ed Ichiye T). Elsevier, Tokyo, pp. 223-230.

Imai M, Ebara S (1989) Year to year change of biomass and the related factors in the Japan Sea. Report of Kuroshio Exploitation and Utilization Research, pp. 263-270, Science and Technology Agency (Tokyo). (in Japanese)

Isoda Y, Korematsu H (1995) Interannual variations of water temperature, salinity and oxity vertical distributions in the Tsushima Current Region. Umi to Sora 71(2): 1-11. (in Japanese)

Kawasaki T (1983) Why do some pelagic fishes have wide fluctuations in their numbers? FAO Fish Rep 291(3): 1065-1080.

Kawasaki T (2003) Recent meanings of the regime shift study. Kaiyo Monthly 35(2): 75-79. (in Japanese)

Kim K-R, Kim K (1996): What is happening in the East Sea (Japan Sea): recent chemical observations during CREAMS 93-96. J Kor Soc Oceanogr 31: 164-172.

Kim K-R, Kim K, Kang D-J, Volkov Y N, Yoon J-H, Takematsu $M$ (2002) The changes in the East/Japan Sea found by CREAMS. Oceanogr Jpn 11: 419-429. (in Japanese)

Kim S-W, Isoda Y (1998) Interannual variations of the surface mixed layer in the Tsushima Current Region. Umi to Sora 74(1): 11-22. (in Japanese)

Kitou M (1967) Phylum Chaetognatha. In: The Encyclopedia of Marine Plankton in Japan, Vol. 5 Phyla Mollusca, Chaetognatha, Order Thaliacea etc. (ed Motoda S). Soyosha, Tokyo, pp. 40-51. (in Japanese)

Klyashtorin L, Smirnov B (1995) Climatic dependent salmon and sardine stock fluctuations in the North Pacific. Can Spec Publ Fish Aquat Sci 121: 179-181.

Kubo N, Ebara S (1992) Long term change of diatom distribution and oceanographic conditions in the sea south of Hokkaido and the Japan Sea. Kenkyu-Jiho (JMA) 44: 107-117. (in Japanese)

Lluch-Belda D, Crawford RJM, Kawasaki T, MacCall AD, Parrish RH, Schwarzlose RA, Smith PE (1989) World-wide fluctuations of sardine and anchovy stocks: the regime problem. S Afr J Mar Sci 8: 195-205.

Mackas DL, Thomson RE, Galbraith M (2001) Changes in the zooplankton community of the British Columbia continental margin, 1985-1999, and their covariation with oceanographic conditions. Can J Fish Aquat Sci 58: 685-702.

Matsumura S, Xie S-P (1998) Response of temperature and precipitation over Japan and the Japan Sea to variability of winter monsoon. Weather 45(10): 31-41. (in Japanese)

Minami H, Hashimoto Y, Konishi Y, Daimon H (1987) Statistical features of the oceanographic conditions in the Japan Sea. Umi to Sora 62: 163-175. (in Japanese)

Minami H, Kano Y, Ogawa K (1999a) Long-term variations of potential temperature and dissolved oxygen of the Japan Sea Proper Water. J Oceanogr 55: 197-205.

Minami H, Kawae S, Nagai N, Jifuku J (1999b) Long-term variability of oceanic conditions along the PM Line in the Japan Sea. Sokko-Jiho (JMA) 66: 63-80. (in Japanese)

Minobe S (2000) Spatio-temporal structure of the pentadecadal variability over the North Pacific. Prog Oceanogr 47: 99-102.

Motoda S (1957) North pacific Standard Plankton net. Info Bull Planktol Jpn 4: 13-15.

Nagasawa K (2001) Long-term variations in abundance of Pacific herring (Clupea pallasi) in Hokkaido and Sakhalin related to changes in environmental conditions. Prog Oceanogr 49: 551-564.

Nagai N, Tadokoro K, Kuroda K, Sugimoto T (2006) Occurrence characteristics of chaetognath species along the PM transect in the Japan Sea during 1972-2002. J Oceanogr 62: 597-606.

Nakadate A, Kubo N, Nishizawa J (2003) Fluctuations of the Japan Sea Proper Water and the Tsushima Warm Current water. Sokko-Jiho (JMA) 70: 19-26. (in Japanese)

Nishihama S, Hirakawa K (1998) Diel vertical migration of chaetognaths in the Tsushima Current of the Japan Sea. Bull Japan Sea Natl Fish Res Inst 48: 71-83. (in Japanese)

Park W-S, Oh IS (2000) Interannual and interdecadal variations of sea surface temperature in the East Asian Marginal Seas. Prog Oceanogr 47: 191-204.

Pyper, Peterman (1998) Comparison of methods to account for autocorrelation in correlation analysis of fish data. Can J Fish Aquat Sci 55: 2127-2140.

Sakurai Y, Kiyofuji H, Saitoh S, Goto T, Hiyama Y (2000) Changes in inferred spawning waters of Todarodes pacificus (Cephalopoda: Ommastrephidae) due to changing environmental conditions. ICES J Mar Sci 57: 24-30.

Sekine Y (1992) On the oceanic circulation in the Japan Sea. Umi to Sora 67 Spec: $27-38$. (in Japanese)

Senjyu T (2003) Decadal-scale changes of water temperature along Sanin coast of the Japan Sea. Kaiyo Monthly 35(1): 59-64. (in Japanese)

Senjyu T, Sudo H (1996) Interannual variation of the upper portion of the Japan Sea Proper Water and its probable cause. J Oceanogr 52: 27-42.

Shuto K (1982) A review of sea conditions in the Japan Sea ( $\square$ ). Umi to Sora 57(2/3): 94-105. (in Japanese)

Sugimoto T, Kimura S, Tadokoro K (2001) Impact of El Niño events and climate regime shift on living resources in the western North Pacific. Prog Oceanogr 49: 113-127.

Terazaki M (1993) Deep-sea adaptation of the epipelagic chaetognath Sagitta elegans in the Japan Sea. Mar Ecol Prog Ser 98: 79-88.

Terazaki M (2001) Ecology of Chaetognatha. Kaiyo Monthly 
Extra (27): 191-197. (in Japanese)

Tsunogai S, Watanabe YW, Harada K, Watanabe S, Saito S, Nakajima M (1993) Dynamics of the Japan Sea deep water studied with chemical and radiochemical tracers. In: Deep Ocean Circulation, Physical and Chemical Aspects (ed Teramoto T). Elsevier Science Publications B. V., pp. 105-119.

Uda M (1934) The results of simultaneous oceanographic investigations in the Japan Sea and its adjacent waters in May and June 1932. J Imp Fish Exp Stations 5: 57-190. (in Japanese)

Watanabe T, Hanawa K, Toba Y (1986) Analysis of year-to-year variation of water temperature along the coast of the Japan Sea. Prog Oceanogr 17: 337-357.
Yasuda T, Hanawa K (1999) Composite analysis of North Pacific subtropical mode water properties with respect to the strength of wintertime East Asian monsoon. J Oceanogr 55: 531-541.

Yasunaka S, Hanawa K (2002) Regime shifts found in the Northern Hemisphere SST field. J Meteor Soc Jpn 80: 119-135.

Yasunaka S, Hanawa K (2003) Regime shifts in the Northern Hemisphere SST field: Revised in relation to tropical variations. J Meteor Soc Jpn 81: 415-424.

Zhang CI, Lee JB, Kim S, Oh J-H (2000) Climatic regime shifts and their impacts on marine system and fisheries resources in Korean waters. Prog Oceanogr 47: 171-190. 